\title{
Benefits of fixed orthodontic appliances on growth and development in pediatric patients with class III malocclusion
}

\begin{abstract}
For most clinicians it has always been difficult to decide the exact timing to treat a class III malocclusion. This malocclusion can be classified into three types: true skeletal, dental or pseudo class III malocclusion, which usually determines the prognosis. The aim of this article is to demonstrate a simple, effective method for early treatment of class III malocclusion in mixed dentition and to emphasize the benefits of early intervention in the shortest treatment time. In this case, the patient was treated with a fixed $2 \times 4$ appliance on maxillary and mandibular arches for nine months, followed by a retention protocol. Once the treatment was completed, the patient was followed for a six-month period. The results showed that with early intervention it is possible to achieve favorable outcomes in pediatric patients with fixed braces in class III malocclusion. It is concluded that early intervention is mandatory and it should be carried out in all patients, and there should be no second thought in reaching such a decision.
\end{abstract}

Keywords: class III malocclusion, self-ligating appliance, early intervention, anterior crossbite
Volume 7 Issue 4 - 2017

\author{
Abhiyanth S Shetty \\ Department of Orthodontics, Member of World Federation of \\ Orthodontists (WFO), Kuwait
}

Correspondence: Abhiyanth S Shetty, Department of Orthodontics, Member of World Federation of Orthodontists (WFO), Salhiyah Clinic, Salhiya Complex, Gate 4, 4thFloor, Kuwait,Email abhiortho@gmail.com

Received: May 18,2017 | Published: June 06, 2017

\section{Introduction}

The exact timing of orthodontic treatment for children with developing class III malocclusion has always been a controversial topic among clinicians. The main reason for unpredictability in treating class III malocclusion lies in the lack of consensus in understanding the etiology and classifications of malocclusion. ${ }^{1-3}$ Class III malocclusion can be classified into three types: true skeletal, dental and pseudo class III malocclusion, which usually has the same appearance..$^{3,4}$ According to Angle's classification, in class III malocclusion the mesiobuccal cusp of the lower first molar occludes mesial to the class I position. According to British standards, in class III malocclusion the lower incisor edges lie anterior to the cingulum plateau of the upper incisors. In pseudo class III malocclusion there is premature contact between maxillary and mandibular incisors which results in forward displacement of the mandible during posterior occlusion. Proper understanding of the classification of class III malocclusion is important to determine the diagnosis and prognosis. ${ }^{5-8}$ Though it is believed to be genetic there are other environmental factors which may have contribute to a class III malocclusion. Among these are enlarged tonsil, ${ }^{9}$ difficulties in nasal breathing, ${ }^{9}$ congenital anatomic defects, ${ }^{10}$ disease of the pituitary gland, ${ }^{11}$ hormonal disturbances, ${ }^{12}$ habit of protruding the mandible, ${ }^{11}$ posture, ${ }^{11}$ trauma and disease, ${ }^{10}$ premature loss of the sixth year molar, ${ }^{11}$ irregular eruptions of permanent incisors or loss of deciduous incisors, ${ }^{13}$ as well as size and relative positions of the cranial base, maxilla and mandible and the position of the temporomandibular articulation. ${ }^{14-17}$

Although the interaction between genetic and environmental factors is not completely understood in the development of a class
III malocclusion. In pediatric class III patients with moderate to severe anterior crossbite and deep bite will need early intervention. It is widely known that both vertical and anteriorposterior maxillary deficiency can contribute to class III malocclusion. ${ }^{6,15}$ If there is vertical growth deficiency of maxilla, then the mandible rotates forward and upward resulting in mandibular prognathism. In such class III cases many clinicians prefer to treat by using reverse facemask, chincap and Frankel III or functional appliances, which have shown to be effective in modifying cranio-facial complex. ${ }^{18-24}$ Keeping these factors in mind during treatment planning helps to achieve a harmonious relationship between the teeth, jaw and environmental factors, which leads to a good functional relationship at an early age. ${ }^{25}$ In the current study the aim of this article is to demonstrate a simple, effective method for early treatment of class III malocclusion in mixed dentition with 2 X 4 fixed orthodontic appliances and to emphasize the benefits of early intervention in the shortest treatment time compared to other removable functional appliances.

\section{Case presentation}

An 8-year-old boy was referred to Salhiyah Clinic, Kuwait, with complaints of an unpleasant smile and anterior crossbite. Extraoral examination revealed dished facial appearance, retrusive upper lip and protrusive lower lip (Figures $1 \& 2$ ). Intraoral examination showed that the boy had protruded lower anteriors, reverses deep-bite and retained upper right lateral incisor (Figure 3). Lateral cephalometric analysis revealed a skeletal class III relationship with deficient maxilla and severely proclined lower incisors with reverse overjet of $3 \mathrm{~mm}$ and deep bite of $6 \mathrm{~mm}$ (Figures 4-6). 


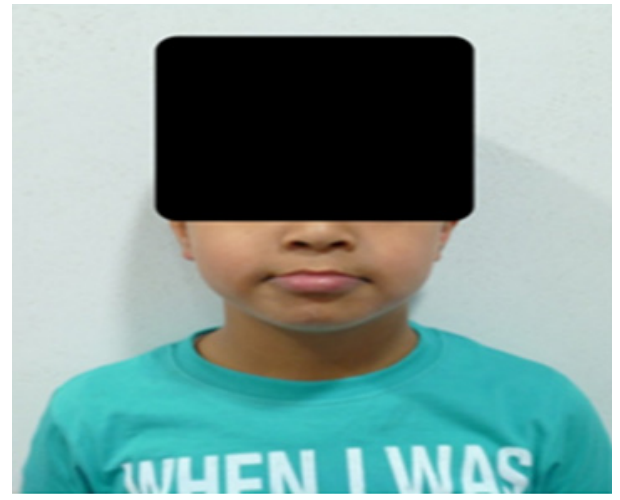

Figure I Pre-treatment frontal view.

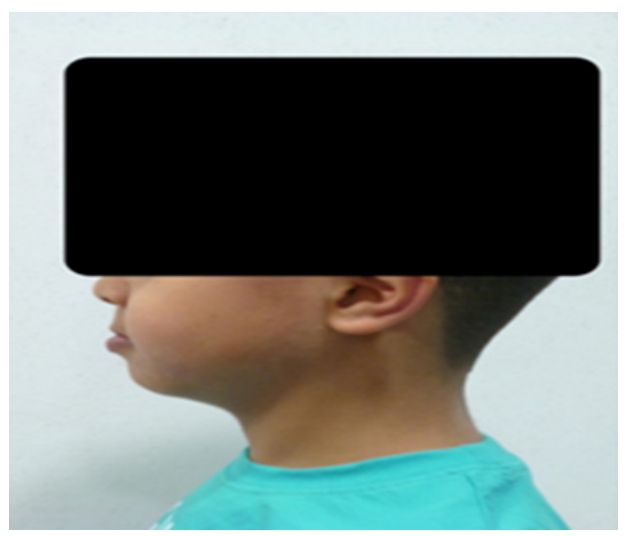

Figure 2 Pre-treatment profile view.
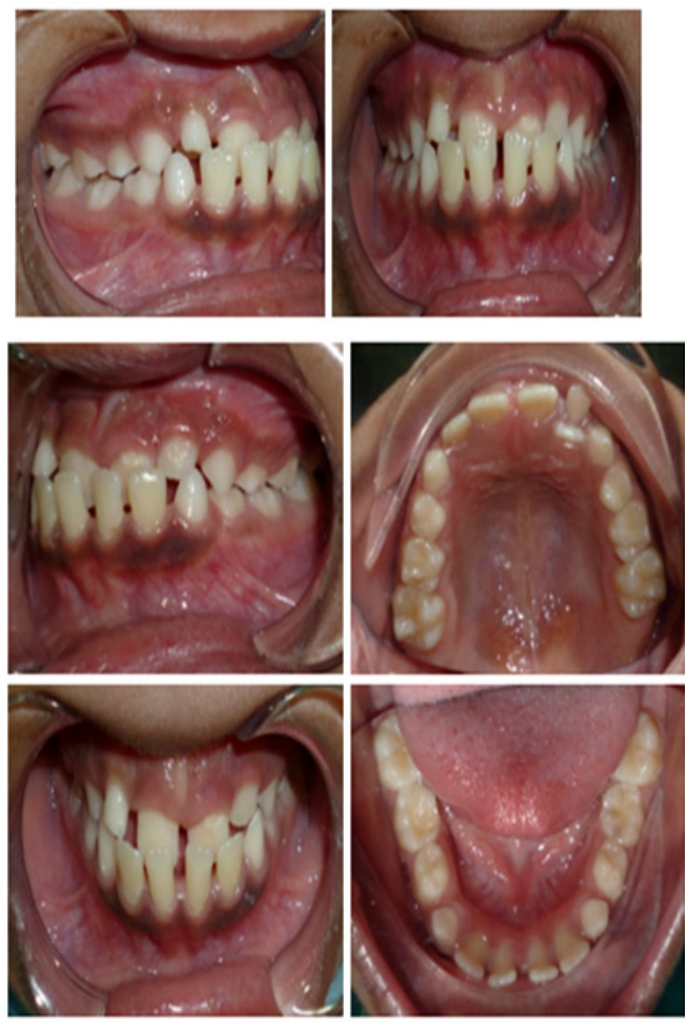

Figure 3 Pretreatment intraoral photos.

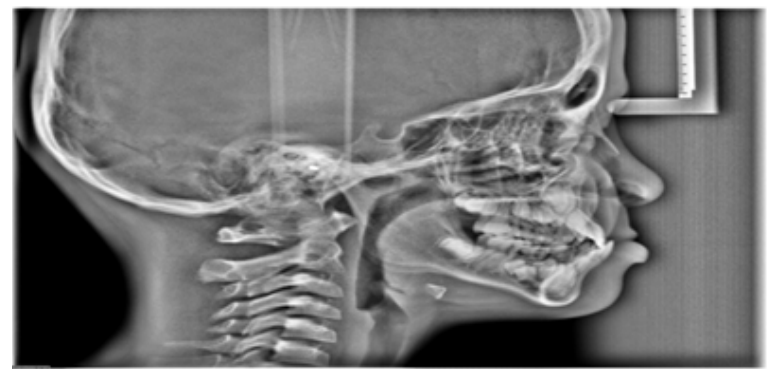

Figure 4 Pre-treatment cephalometric radiograph.

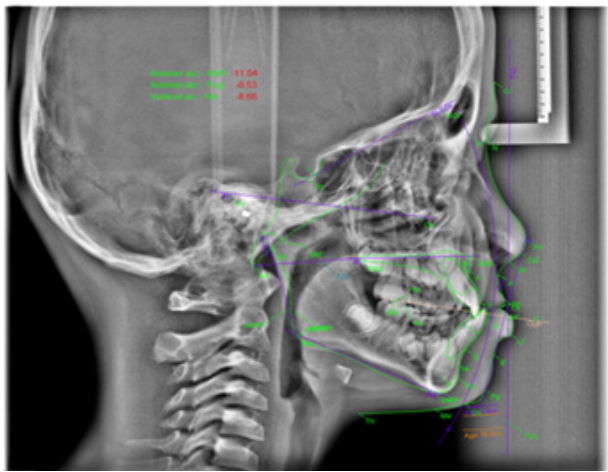

Figure 5 Pre-treatment analyzed cephalometric radiographs.

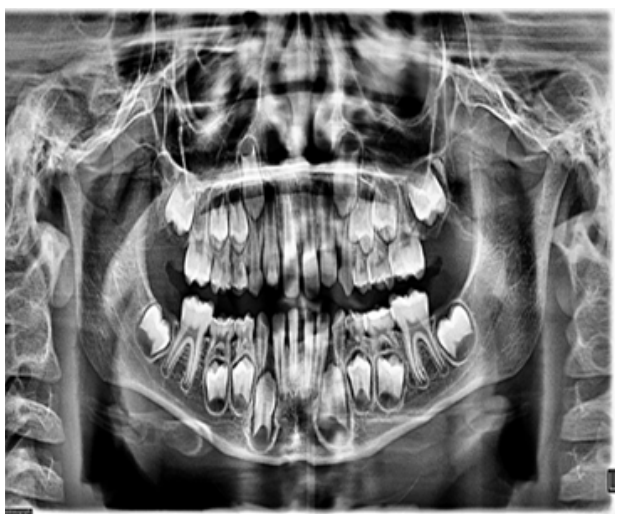

Figure 6 Pre-treatment panoramic radiographs.

\section{Treatment objectives}

The primary goal is to remove any obstruction which may hamper the normal growth and development of the jaws. So our treatment objectives were (1) to improve facial appearance, (2) to improve the skeletal jaw relationship between maxilla and mandible and (3) to establish correct anterior occlusion with ideal overjet and overbite.

\section{Treatment alternative}

Based on the objective, two treatment options were considered. Option one was a reverse face mask with removable upper and lower plate. The upper plate contained posterior bite blocks with protraction springs or expansion screw, which was placed in the anterio-posterior direction. The lower plate contained a labial bow for retraction of lower anteriors. The second option was fixed $2 \times 4$ orthodontic appliance. The parents opted for second option as the patient was too young to wear or cooperate with any kind of orthopedic or removable appliances. 


\section{Methods}

All diagnostic records were taken at the start and end of the treatment. The cephalometric analysis was carried out with the dentofacial planner AudaxCeph. Metal self-ligating brackets of 022 slot with MBT prescription (Noble Stahl German Brackets) were bonded on upper and lower incisors. A molar tube was bonded on upper and lower second deciduous molars. At the first visit of the treatment, bite blocks were placed on upper second deciduous molars with brackets bonded on lower incisors. Initial level and alignment was done by a 0.014 niti (NITI Ormco Corporation) wire with very light e-chain from 2-2 (Figure $7 \& 8$ ). At the second-month appointment, maxillary right deciduous lateral incisors were extracted and it was observed that due to tongue pressure the in-standing permanent right lateral incisor was pushed labially. Later all four upper incisors were bonded for leveling and aligning. By the end of 5 months, the anterior crossbite was eliminated and incisors were aligned. After level and alignment, the maxillary incisors were proclined by placing active wire. The activation of wire was done by placing stop lock mesial to the second deciduous molars and then inserting the wire into the brackets of incisors. Once the anterior crossbite was eliminated and the incisors were aligned, spaces on maxillary and mandibular anteriors were closed by using e-chain. The lower appliance was taken off around the seventh month of treatment (Figure 9). During the process of space closure, the wire sequence was gradually increased for torqueing the anteriors. The total correction of anterior crossbite and forward mandibular displacement was achieved within 9 months by retraction of lower anteriors and torqueing upper incisors. The wire sequence used were: 14 niti, 16 niti, 14 X 25 niti, 16 X 25 niti, 19 X 25 niti and stabilization was done with 19 X 25 SS wire. After torque application was completed, the teeth were held with e-chain for 3 weeks and an appointment was booked for braces off. After the end of active treatment, the retention was achieved by bonded fixed lingual retainer on maxillary and mandibular incisors with Essex retainer and class III elastics worn at night time only. The bite blocks on maxillary second deciduous molars were reduced gradually to facilitate eruption of molars until they were in occlusion.
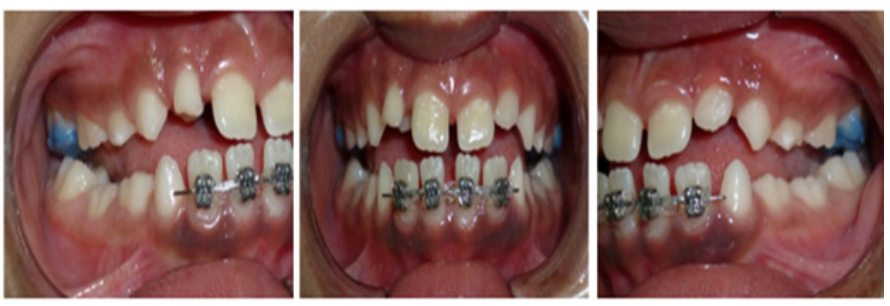

Figure 7 First month intraoral photos.
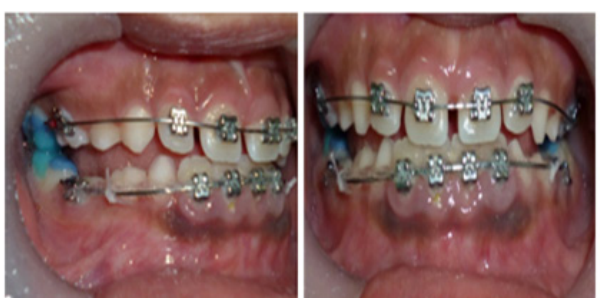

Figure 8 Fifth month intraoral photos.
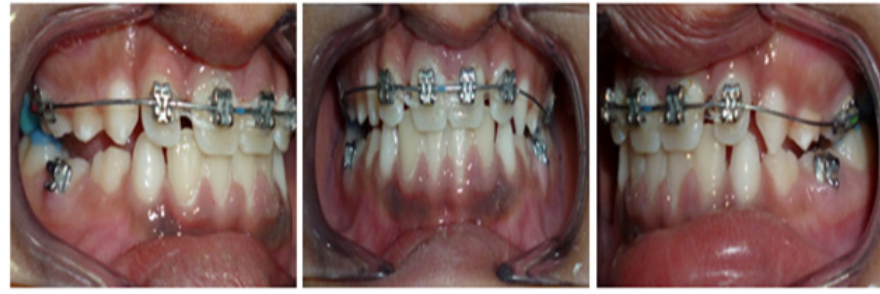

Figure 9 Seventh month intraoral photos.

\section{Results}

The positive overjet, overbite with class I incisors were achieved via dento-alveloar compensation (Figure 12). The angulation of upper incisors to palatal plane showed an increase by 60 , while the angulation of lower incisors to the mandibular plane showed a decrease by 50 . The position of maxilla in relation to $\mathrm{SN}$ has increased by 60 . The relationship between maxilla and mandible has decreased from $-6 \mathrm{~mm}$ to $-2 \mathrm{~mm}$ (Table 1). By the end of the treatment we could manage to achieve all our objectives including functional occlusion, pleasant smile with acceptable facial profile (Figure $10 \& 11$ ).

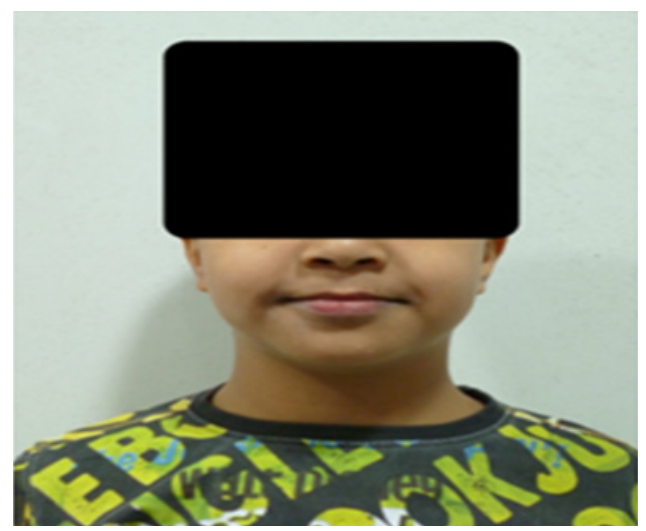

Figure 10 Post-treatment frontal view.

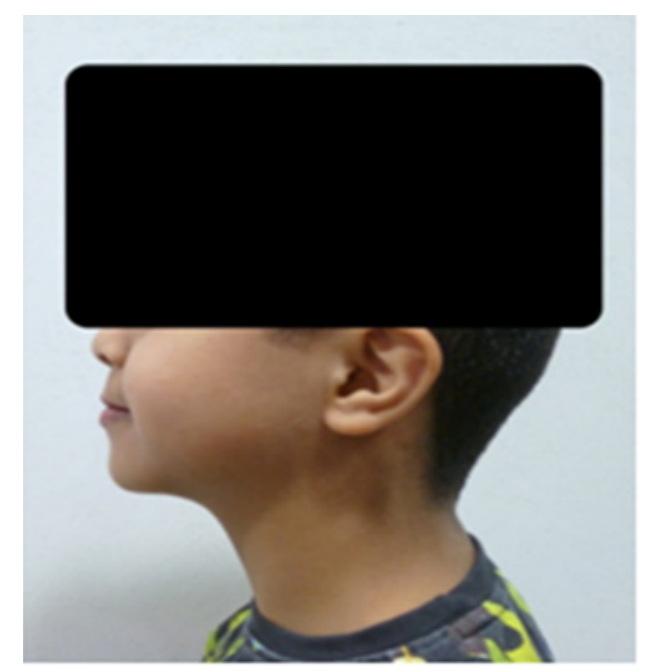

Figure I I Post-treatment profile view. 

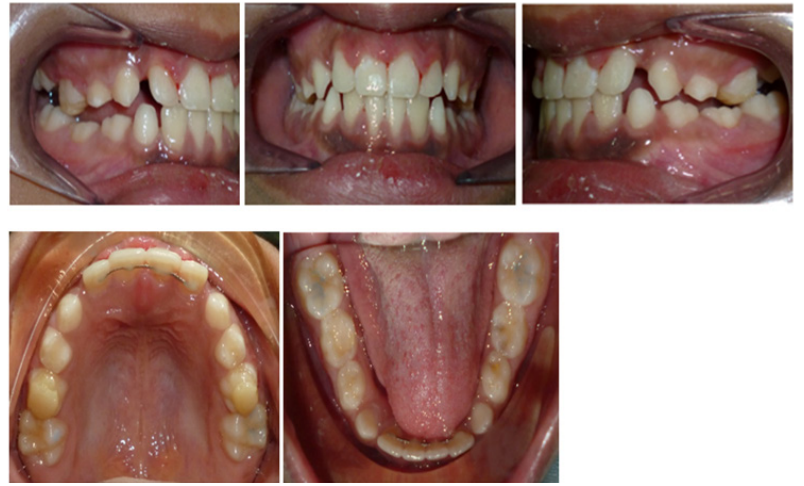

Figure 12 Post-treatment intraoral photos.

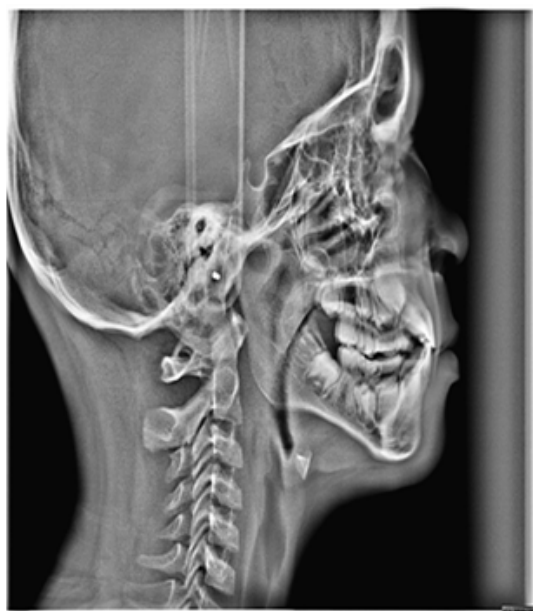

Figure I 3 Post-treatment cephalometric radiographs.

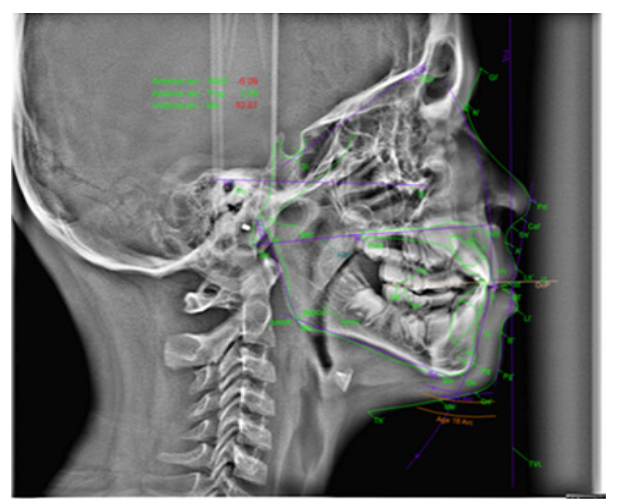

Figure I 4 Post-treatment analyzed cephalometric radiographs.

Table I Comparison of pre- and post-treatment cephalometric values

\begin{tabular}{llll}
\hline Measurements & $\begin{array}{l}\text { Normal } \\
\text { Value }\end{array}$ & $\begin{array}{l}\text { Pre- } \\
\text { Treatment }\end{array}$ & $\begin{array}{l}\text { Post- } \\
\text { Treatment }\end{array}$ \\
\hline SNA & 820 & 750 & 810 \\
SNB & 800 & 760 & 790 \\
ANB & 20 & -30 & 20 \\
Wits & 0 & $-6 \mathrm{~mm}$ & $-2 \mathrm{~mm}$ \\
Anterior arc-ANS & 0 & $-10 \mathrm{~mm}$ & $-6 \mathrm{~mm}$ \\
Anterior arc-Pog & 0 & $1 \mathrm{~mm}$ & $1 \mathrm{~mm}$ \\
\hline
\end{tabular}

\begin{tabular}{llll}
\hline Measurements & $\begin{array}{l}\text { Normal } \\
\text { Value }\end{array}$ & $\begin{array}{l}\text { Pre- } \\
\text { Treatment }\end{array}$ & $\begin{array}{l}\text { Post- } \\
\text { Treatment }\end{array}$ \\
\hline Nasolabial angle & 1020 & 1070 & 1200 \\
ML-SN & 320 & 380 & 360 \\
SN/Ocp & 140 & 220 & 150 \\
Gonial angle & 1220 & 1300 & 1300 \\
+ I/NA & 220 & 270 & 320 \\
+ I/NL & 1150 & 1180 & 1240 \\
- I/NB & 250 & 330 & 300 \\
- I/ML & 900 & 990 & 940
\end{tabular}

SNA, sella nasion point $A ; S N B$ - sella nasion point $B ; A N B$, point a nasion point $\mathrm{B}$; ANS, anterior nasal spine; POG, pogonion; $\mathrm{ML}$, mandibular plane; $\mathrm{SN}$, sella and nasion plane; OCP, occlusal plane; +I, upper incisor; - I, lower incisor; NA, nasion Point $A$; NL, palatal plane; NB, nasion Point $B$

\section{Discussion}

Once the clinician is able to diagnose the class III malocclusion at the developing stage, treatment must be performed as soon as possible. Correcting anterior crossbite allows normal dental base and skeletal growth, avoids habits like bruxism, eliminates any kind of traumatic occlusion, ${ }^{25-42}$ reduces treatment time in phase 2 if required, ${ }^{28}$ can avoid surgery, minimizes the need for comprehensive treatment or even eliminates the need for any further treatment in permanent dentition, ${ }^{32}$ minimizes psychological issues and increases selfesteem, ${ }^{43}$ and consequently increases the maxillary arch perimeter and avoids any kind of extraction of permanent teeth in phase 2 treatment. ${ }^{44}$ The inclination of the maxillary and mandibular incisors has an important influence on facial harmony and aesthetics and this is achieved by $2 \times 4$ fixed braces on both arches. Compensatory treatment of class III malocclusion has been achieved by proclining upper incisors from 1180 to 1240 and retroclining lower incisors from 990to 940. Cephalometric analysis shows that the SNA angle has been increased from 750 to 810 and wits has decreased from $-6 \mathrm{~mm}$ to $-2 \mathrm{~mm}$ with acceptable incisor position on basal bone. Most class III malocclusions will be either dental or pseudo, and if not treated at an early stage can turn into full blown skeletal class III malocclusion. By using simple techniques, occlusal interference was eliminated to achieve the correct dento-alveolar relationship. The success of orthodontic treatment in a growing patient with developing skeletal class III malocclusion depends upon three important factors: the person's individual growth potential, timing and cooperation of the patient. ${ }^{26}$ There are numerous ways of planning treatment to treat such patients but patient compliance is critical to the success of any treatment, particularly one that uses a removable appliance. The percentage of class III malocclusion is rather small in number when compared to any other type of malocclusion, but it is the most difficult to treat. Many authors believe that early intervention in the early mixed dentition as well as in the deciduous dentition is an advantage. ${ }^{25}$ Most authors suggest that the ideal age for early intervention is between six to nine years. ${ }^{8-40}$ However, most clinicians still avoid early correction in deciduous dentition because of poor stability, difficult to predict the growth, lack of experience in treating younger patients as well as frustration in getting the child to cooperate. ${ }^{31}$ Therefore most clinicians prefer to wait till all maxillary incisors are erupted before starting the treatment. ${ }^{32}$ The various treatment plans suggested for the correction of an anterior crossbite, and which may correct skeletal and dental 
problems in young patients, include: facemask therapy, ${ }^{33}$ chincaps, ${ }^{30}$ functional appliances, ${ }^{34}$ fixed brace ${ }^{32-35}$ and removable appliances. ${ }^{36}$ According to Tweed, ${ }^{30}$ pseudo class III malocclusion should be treated as early as four years of age if abnormality is diagnosed in primary dentition. If early intervention is not done at an early age, then there will be lingual locking of the maxillary incisors which will retard the growth of the maxilla and accelerate the growth of the mandible. If this condition remains untreated throughout the entire growth period, it will result in severe facial deformity and end up in jaw surgery. Graber $^{38,39}$ advocates to treat the malocclusion as early as possible to intercept the developing malocclusion and basal mal-relationship. Salzmann ${ }^{40}$ suggested treating class III malocclusion as soon as the abnormality is diagnosed. Therefore, there is an increase in the number of clinicians who believe in early intervention. ${ }^{45,46}$

\section{Conclusion}

Early orthodontic intervention should be carried out in all patients, to prevent the existing problems from getting worst. However, the early intervention with fixed orthodontic appliances can minimise or eliminate the need for comprehensive treatment in future.

There is no doubt that by treating these case for few months with fixed braces resulted in:

1. Elimination of forward displacement of the mandible into class III malocclusion during occlusion.

2. Created more favourable environment for normal growth and development of jaws.

3. Improved occlusal relationships.

4. Elimination of traumatic occlusion

5. Space closure and retraction of proclined lower anteriors.

6. Space closure and well aligned upper anteriors.

7. Achieved acceptable facial esthetics for more normal psychosocial development.

\section{Acknowledgments}

None.

\section{Conflicts of interest}

The author declares that there is no conflict of interest.

\section{References}

1. English JD, Sercan Akyalcin, Timo Peltomaki, et al. Orthodontic review USA: Mosby; 2009. p. 1-368.

2. Reyes A, Luis Serret, Marcos Peguero, et al. Case report- Diagnosis and treatment of pseudo class III malocclusion. Case Reports in Dentistry. 2014. p. 1-6.

3. Mammandras AH. Orthodontic treatment of pseudo class III malocclusion. A case report. J Can Dent Assoc. 1984;50(10):779-781.

4. Rabie AB, Gu Y. Diagnostic criteria for pseudo class III malocclusion. Am J Orthod Dentofacial Orthop. 2000;117(1):1-9.

5. Angle EH. Treatment of malocclusion of the teeth and fractures of the maxillae: Angle's system. 6th ed. Philadelphia, USA: SS White Dental Manufacturing; 2000.
6. Guyer EC, Edward E Ellis, James A McNamara, et al. Components of class III malocclusion in juveniles and adolescents. Angle Orthod. 1986;56:7-30.

7. Moyers RE. Handbook of Orthodontics. 4th ed. Year Book Medical Publishers: USA; 1988.

8. Graber TM. Dentofacial orthodontics with functional appliance. 2nd ed USA: Mosby Publishers; 1997.

9. Angle EH. Treatment of malocclusion of the teeth. 7th ed. USA: SS White Dental Manufacturing Company; 1907.

10. Monteleone L, Duvigneaud JD. Prognathism. J Oral Surg. 1963;21:190 195.

11. Gold JK. A new approach to the treatment of mandibular prognathism. Am J Orthod. 1949;35(12):893-912.

12. Pascoe JJ, HaywardJR, Costich ER. Mandibular prognathism: Its etiology and a classification. J Oral Surg. 1960;18:21-24.

13. Rubbrecht O. A study of the heredity of the anomalies of the jaws. Am J Orthod Oral Surg. 1939;25:751-779.

14. Bjork A. Some biological aspects of prognathism and occlusion of teeth Acta Odontol Scand. 1950; 9(1):1-40.

15. Hopkin GB, Houston, James. The cranial base as an etiological factor in malocclusion. Angle Orthod. 1968;38:250-255.

16. Williams S. The morphology of the potential class III skeletal pattern in the young child. Am J Orthod. 1986;89:302-311.

17. Kerr WJS, Tenhave TR. A comparison of three appliance systems in the treatment of class III malocclusion. Eur J Orthod. 1988;10(3):203-214.

18. Irie M, Nakamura S. Orthopedic approach to severe skeletal class III malocclusion. American Journal of Orthodontics \& Dentofacial Orthopedics. 1975;67(4):377-392.

19. Graber LW. Chincup therapy for mandibular prognathism. American Journal of Orthodontics \& Dentofacial Orthopedics. 1977;72(1):59-69.

20. Vego L. Early orthopaedic treatment for class III skeletal pattern. American Journal of Orthodontics \& Dentofacial Orthopedics. 1976;70(1):59-69.

21. McNamara JA. An orthopaedic approach to the treatment of class III malocclusion in young patients. J Clin Orthod. 1987;22(9):598-608.

22. Turley P. Orthopedic correction of class III malocclusion with palatal expansion and custom protraction headgear. J Clin Orthod. 1988;22(5):314-325

23. Frankel R. Maxillary retrusion in class III and treatment with the function corrector III. Trans European Orthodontic Society. 1970. p. 249-259.

24. Robertson N. An examination of treatment changes in children treated with function regulator of Frankel. American Journal of Orthodontics \& Dentofacial Orthopedics. 1983;22:314-325.

25. Beena JP. Cost effective treatment of pseudo class III malocclusion in a permanent dentition with a simple removable appliance. J Case Rep Stud. 2015;3(3):1-5.

26. Kanno Z, Yoonji Kim, Kunimichi Soma. Early correction of a developing skeletal class III malocclusion. Angle Orthod. 2007;77(3):549-556.

27. Rodrigues MA, Almeida RR, Oltramari-Navarro PV, et al. Early treatment of class III malocclusion:10 year clinical follow up. J Appl Oral Sci. 2011;19(4):431-439.

28. Giancotti A, Maselli A, Mampieri G, et al. Pseudo class III malocclusion treatment with Balters Bionator. J Orthod. 2003;30(3):203-215. 
29. Allen RA, Connolly IH, Richardson A. Early treatment of class III incisor relationship using the chin cap appliance. Eur J Orthod. 1993;15(5):371376.

30. Nanda R. Protraction of maxilla in rhesus monkeys by controlled extraoral forces. Am J Orthod Dentofac Orthop. 1978;74:121-141.

31. Turley PK. Orthopedic correction of class III malocclusion: Retention and phase II therapy. J Clin Orthod. 1996;30(6):313-324.

32. Rabie AB, Gu Y. Management of pseudo class III malocclusion in southern Chinese children. Br Dent J. 1999;186(4):183-187.

33. Dos Santos-Pinto A, Paulin RF, Melo AC. Pseudo class III treatment with reverse traction: case report. J Clin Pediatr Dent. 2001;25(4):267-274.

34. Eganhouse GR. Two piece corrector for class III skeletal and dental malocclusion. J Clin Orthod. 1997;31(4):246-251.

35. Lee BD. Correction of crossbite. Dent Clin North Am. 1978;22(4):647668 .

36. Ngan P, Hägg U, Yiu C, et al. Treatment response to maxillary expansion and protraction. Eur J Orthod. 1996;18(2):151-168.

37. Tweed CH. Clinical Orthodontics. The C. V. Mosby Company: USA; 1966.
38. Graber TW. Current orthodontic concepts and techniques. 2nd ed. USA: WB. Saunders Company; 1969. p. 1-1137.

39. Graber TW. Orthodontic: Principles and practice. USA: W. B. Saunders Company; 1966. p. 1-805.

40. Salzmann JA. Practice of orthodontics. Philadelphia and Montreal. USA: JB Lippincott Company; 1966.

41. Albarakati SF. Treatment of a pseudo class III relationship in the mixed dentition: A case report. SDJ. 2007;19(2):119-125.

42. Major PW. Treatment of anterior crossbite in early mixed dentition. J Can Dent Assoc. 1992;58:574-579.

43. Shaw WC, Meek SC, Jones DS. Nicknames, teasing, harassment and salience of dental features among school children. $\mathrm{Br} J$ Orthod. 1980;7(2):75-80.

44. Turley PK. Treatment of the class III malocclusion with maxillary expansion and protraction. Semin Orthod. 2007;13(3):143-157.

45. Turley PT. Early management of the developing class III malocclusion. Aust Orthod J. 1993;13:19-22.

46. Campbell PM. The dilemma of class III treatment/early or late? Angle Orthod. 1983;53(3):175-191. 